\title{
Price, tax and tobacco product substitution in Zambia: findings from the ITC Zambia Surveys
}

\author{
Michal Stoklosa, ${ }^{1}$ Fastone Goma, ${ }^{2}$ Nigar Nargis, ${ }^{1}$ Jeffrey Drope, ${ }^{1}$ Grieve Chelwa, ${ }^{3}$ \\ Zunda Chisha, ${ }^{4}$ Geoffrey T Fong ${ }^{5,6,7}$
}

- Additional material is published online only. To view please visit the journal online (http://dx.doi.org/10.1136/ tobaccocontrol-2017-054037).

${ }^{1}$ Economic and Health Policy Research, American Cancer Society, Atlanta, Georgia, USA ${ }^{2} S$ chool of Medicine, University of Zambia, Lusaka, Zambia ${ }^{3}$ Graduate School of Business, University of Cape Town, Cape Town, South Africa

${ }^{4}$ School of Economics, University of Cape Town, Cape Town, South Africa

${ }^{5}$ Department of Psychology, University of Waterloo, Waterloo, Ontario, Canada

${ }^{6}$ School of Public Health and Health Systems, University of Waterloo, Waterloo, Ontario, Canada

${ }^{7}$ Ontario Institute for Cancer Research, Toronto, Ontario Canada

\section{Correspondence to}

Michal Stoklosa, American Cancer Society, Atlanta, GA 30303, USA;

michal.stoklosa@cancer.org

Received 9 September 2017 Revised 26 January 2018 Accepted 9 February 2018 Published Online First 24 March 2018

\section{ABSTRACT \\ Background In Zambia, the number of cigarette users is growing, and the lack of strong tax policies is likely an important cause. When adjusted for inflation, levels of tobacco tax have not changed since 2007. Moreover, roll-your-own (RYO) tobacco, a less-costly alternative to factory-made (FM) cigarettes, is highly prevalent.}

Data and methods We modelled the probability of FM and RYO cigarette smoking using individual-level data obtained from the 2012 and 2014 waves of the International Tobacco Control (ITC) Zambia Survey. We used two estimation methods: the standard estimation method involving separate random effects probit models and a method involving a system of equations (incorporating bivariate seemingly unrelated random effects probit) to estimate price elasticities of FM and RYO cigarettes and their cross-price elasticities.

Results The estimated price elasticities of smoking prevalence are -0.20 and -0.03 for FM and RYO cigarettes, respectively. FM and RYO are substitutes; that is, when the price of one of the products goes up, some smokers switch to the other product. The effects are stronger for substitution from FM to RYO than vice versa. Conclusions This study affirms that increasing cigarette tax with corresponding price increases could significantly reduce cigarette use in Zambia. Furthermore, reducing between-product price differences would reduce substitution from FM to RYO. Since RYO use is associated with lower socioeconomic status, efforts to decrease RYO use, including through tax/price approaches and cessation assistance, would decrease health inequalities in Zambian society and reduce the negative economic consequences of tobacco use experienced by the poor.

\section{INTRODUCTION}

Tobacco use in Zambia is on the rise. The WHO projects that the number of current smokers in Zambia will increase from 1.2 million in 2015 to 1.5 million in 2025 , primarily due to population growth. ${ }^{1}$ The most current survey of smoking prevalence in Zambia was the International Tobacco Control Policy Evaluation (ITC) Survey, which found that $10.7 \%$ of adults $(22.7 \%$ of men and $0.7 \%$ of women) aged 15-49 smoked cigarettes in Zambia in 2014 (table 1). ${ }^{2}$ The increase in tobacco use has imposed a heavy burden on Zambian society. Estimates show that the number of tobacco-related deaths in Zambia increased from 3000 per year (43 per 100 000) in 1990 to 8000 per year (46 per 100 000) in $2015 .^{3}$ Tobacco use is also a burden on Zambia's economic development. The costs of smoking include health expenditures and productivity losses and costs associated with undernutrition and underinvestment in education, as spending on tobacco products has been shown to divert resources from essential goods and services in Zambia. ${ }^{4}$

A primary reason for the rise in tobacco use in Zambia is the low price of cigarettes. When adjusted for inflation, ${ }^{5}$ the price of factory-made (FM) cigarettes has been falling (figure 1 ). In addition, cigarette prices have not kept pace with rising disposable incomes in Zambia. ${ }^{6}$ These price dynamics have led to significantly greater affordability of cigarettes. With only $12.9 \%$ of per capita gross domestic product needed to purchase 100 packs of the most popular brand in 2016, the affordability of cigarettes in Zambia was greater than in the average African country (13.5\%). ${ }^{7}$ Population survey data also point to the high affordability of cigarettes in Zambia; only $27 \%$ of male smokers and quitters from the ITC Zambia Survey reported that the price of cigarettes led them to think about quitting, the third lowest percentage among 20 countries surveyed by the ITC. ${ }^{2}$

The most effective way to increase cigarette prices and thus decrease cigarette consumption and prevalence is through tobacco tax increases. ${ }^{8}$ Despite high, often double-digit, inflation and rapid income growth, tobacco taxes have rarely increased in Zambia. The country's cigarette excise tax is an ad valorem tax, with a specific tax floor. ${ }^{6}$ The current ad valorem excise tax rate, at $145 \%$ of the Cost, Insurance and Freight value for imported cigarettes or the Producer Price value for domestically produced cigarettes, was introduced in 2007 but has not changed since. ${ }^{6}$ The 2016 budget increased the specific tax floor from 90 kwacha (US\$8.72) to 200 kwacha (US\$19.37) per 1000 sticks, but this represents a mere adjustment for inflation back to the tax levels at introduction in 2007. ${ }^{9}$ Consequently, Zambia has one of the lowest tax shares in the world. In 2016, tax comprised only $37 \%$ of the retail price of cigarettes of the most popular brand, compared with $56 \%$ globally. ${ }^{7}$ WHO recommends a tax share of $75 \% .^{8}$

Aside from low tobacco taxes, efforts to reduce tobacco use in Zambia are undermined by the availability of a substitute to FM cigarettes: roll-your-own (RYO) tobacco. In 2014, 39\% of Zambian smokers smoked only or primarily RYO cigarettes, and $88 \%$ of them indicated a lower price as the main reason for their use of RYO. ${ }^{2}$ Although the ad valorem excise tax rate for RYO is the same as for FM cigarettes, in the ITC Survey, the users report RYO to be significantly less expensive than FM cigarettes. ${ }^{2}$ Consequently, after each cigarette 
Table 1 Prevalence of tobacco use among adults aged 15-49 in Zambia from the ITC Project Zambia Survey, 2014

\begin{tabular}{lccl}
\hline & $\begin{array}{l}\text { Both } \\
\text { sexes, \% }\end{array}$ & Males, \% & Females, \% \\
\hline Any tobacco use & 13.20 & 23.60 & 3.30 \\
1. Smokeless tobacco use & 2.38 & 0.94 & 2.61 \\
2. Cigarette use & 10.69 & 22.66 & 0.66 \\
\hline Only or primarily FM cigarette use & 6.31 & & \\
Only or primarily RYO cigarette use & 4.17 & & \\
Dual use & 0.21 & & \\
\hline
\end{tabular}

*ITC Project Zambia Survey, $2014 .^{2}$

FM, factory made; ITC, International Tobacco Control; RYO, roll your own.

tax increase, instead of quitting or cutting back, some smokers likely switch to the less expensive RYO cigarette products.

When the ratio of tobacco product prices changes, consumers are expected to switch to relatively cheaper products. ${ }^{10}$ The exact effects of prices for FM and RYO cigarettes on tobacco use are not known. A recent survey of the evidence from the US National Cancer Institute and WHO concluded that research on cross-price effects is scarce and practically non-existent for low-income and middle-income countries (LMICs). ${ }^{11}$ To date, only one study from sub-Saharan Africa has investigated the impact of product prices on substitution among tobacco products. ${ }^{12}$ That study used data from Income Expenditure Surveys in South Africa and found substitution between cigarettes and other tobacco products in response to relative price changes, but the magnitude of these effects was not calculated. Therefore, it is still unclear how changes in the prices of FM and RYO cigarettes influence cigarette use. Our study in Zambia aims to shed light on this relationship.

\section{METHOD}

\section{Data source}

We used longitudinal data from two waves of the ITC Zambia Survey, which were conducted from September to December 2012 (Wave 1), and from August to October 2014 (Wave 2). The ITC Zambia Survey is a nationally representative, face-to-face survey conducted on a cohort sample of approximately 1500 tobacco users and 600 non-users in each wave. The retention rate for smokers was $61 \%$, with respondents lost to attrition being replenished from the same sampling frame at Wave 2. Additional methodological details for the survey can be found on the ITC Project website. ${ }^{13}$

Because our focus was the impact of prices on cigarette use, survey responses for which the price of cigarettes could not be assigned were excluded from the study. As a result, the analysis was conducted on a sample of 2575 individuals (both smokers and non-smokers), of whom 1165 appeared in both waves, yielding 3740 observations.

\section{Measures}

In order to estimate the impact of cigarette prices on cigarette use in Zambia, the analysis involves modelling the probability of the discrete choice of whether an individual currently smokes. Because cigarette smoking is associated with significant health risks for even light smokers (1-4 cigarettes per day), ${ }^{14}$ in this study, we decided to focus on smoking status and not smoking intensity, as this is a more clinically meaningful measure.

The primary explanatory variables in this analysis are prices of FM and RYO cigarettes, as reported by the survey respondents. It is possible to derive self-reported cigarette prices from the ITC Zambia Survey in two ways. First, respondents reported the number of cigarettes or amount of RYO tobacco purchased during their last tobacco purchase and the price paid. The answers to these questions allowed us to calculate the price per cigarette stick that they paid.

The amount of loose tobacco for RYO cigarettes was reported either in grams or in various other quantities and container sizes (eg, '4 tablespoons'). For responses that were not in grams, but where the amount of tobacco purchased was still identifiable, we converted the reported amount of tobacco into grams. ${ }^{15}$ Prices per gram of RYO cigarettes were then converted to price per RYO stick, using the conversion of 0.92 g per stick from the US Master Settlement Agreement. ${ }^{16}$ As a robustness check, we also used an alternative conversion of 0.7 grams per stick, ${ }^{17}$ but this did not change results materially (see online supplementary appendix table S1).
25

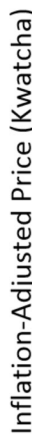

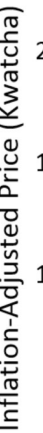

200220032004200520062007200820092010201120122013201420152016

$1,400,000$

$1,200,000$

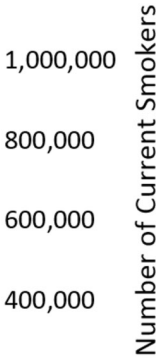

200,000

\section{0}

Number of current smokers

Figure 1 Inflation-adjusted cigarette prices and the number of current smokers from 2002 to 2016 in Zambia. Price of factory-made cigarettes (local brand; pack of 20; midpriced store) from the Economist Intelligence Unit ${ }^{21}$; inflation from the International Monetary Fund ${ }^{5}$; and number of current smokers from the WHO. ${ }^{1}$ 
The second method used to derive the cigarette price data from the ITC Survey was to use the reported sum of money spent on cigarettes in the last 30 days. This information, combined with the information on the number of cigarettes smoked each day, allowed us to calculate the price per stick. The method assumes that, on average, cigarettes purchased in the last 30 days were also consumed in that period. This should be the case in Zambia, as about half of smokers purchased loose (single) cigarettes in $2014,{ }^{2}$ which does not suggest stockpiling. The ITC Survey does not collect separate data on the number of FM and RYO cigarettes smoked per day, but rather collects information on the total number of cigarettes smoked. Therefore, the spending-based price of FM and RYO could not be calculated for those who were dual users of FM and RYO (23\% of smokers in our sample).

Both price measures are subject to recall bias. With some values of the last-purchase price and the spending-based price being clearly misreported, we did not use prices that were outliers for both measures ( \pm 2 SDs from the survey wave mean). Apart from being subject to a recall bias, the spending-based price measure can also be subject to under-reporting bias, as people tend to under-report the number of cigarettes they smoke per day. ${ }^{18}$ Therefore, when calculating both RYO and FM prices for each individual, we first used the self-reported price from the last purchase as the more reliable price, and then used the spending-based price only if the last-purchase price was not available. We incorporated the redenomination of the Zambian kwacha that occurred in 2013, when the old currency unit was divided by 1000 . The prices from the first wave were also adjusted for inflation, so that all prices used in the analysis are in 2014 kwacha.

One obstacle to using self-reported prices in estimating the demand equations is that prices may be endogenous from the simultaneity of price and consumption. To address this problem, the prices of FM and RYO were averaged by geographical regions (primary sampling units, $\mathrm{n}=20$ ) and by wave. These averaged prices were then assigned to both smokers and non-smokers in the given region and wave. This technique was used by Nargis and colleagues in their analysis of similar data from the ITC Bangladesh Survey. ${ }^{19}$ In one geographical region, no FM price was reported in both waves, while in another one, no RYO price was reported in Wave 2. In those instances, prices could not be assigned; hence, those observations $(n=284)$ were excluded from the study.

A concern with this approach is that changes in prices observed across regions and waves may result from actual price changes, but because of differences in smokers' purchasing behaviours, due to, for example, differences in their socioeconomic status. To address this concern, in another approach, we first regressed prices of FM and RYO on geographical regions and waves as well as household characteristics (income status, residence in an urban area and residence in the capital city of Lusaka) and form of tobacco purchased (single stick cigarettes/pack of cigarettes/carton of cigarettes/handrolled tobacco). The models' fitted values were then predicted for both smokers and non-smokers and used as explanatory variables in models of smoking status. The results from those models are presented in the online supplementary appendix.

Another explanatory variable is respondents' per capita household income. The analysis uses a categorical variable for the income status of individuals in relation to the international poverty lines of $\$ 1.25$ and $\$ 2.00$ per person per day. ${ }^{20}$ Because $12 \%$ of respondents did not report their income, we added the missing response as one of the categories. As a result, the income variable includes four categories: income below $\$ 1.25$ (reference group), income from $\$ 1.25$ to $\$ 1.99$, income at $\$ 2.00$ and above and income not reported. As a robustness check, we also used multiple imputation to estimate the missing income categories. Including the imputed income in the models did not change the results materially (see online supplementary appendix table S2). Other explanatory variables include participants' age, a dummy variable for gender, a dummy variable for residence in an urban area, a dummy variable for residence in Lusaka, a categorical variable for educational attainment, a dummy variable for occupation in a white-collar job and a dummy variable for self-reported health status as good/excellent.

\section{Analysis}

The analysis includes a model for current use of any cigarettes (FM and RYO), separate models for smoking status for FM and RYO, as well as a model for dual cigarette use (both FM and $\mathrm{RYO}$ ).

Random effects probit models in the following functional form were used to estimate the probability of cigarette smoking participation (model 1), the probability of RYO and FM cigarette smoking participation (models 2 and 3), as well as the probability of dual use (model 4):

Model 1, 2, and 3:

$$
\begin{aligned}
& \operatorname{Pr}\left(\text { current }_{\text {smoker }}{ }_{i t}=1 \mid \text { Price }_{i t}, \text { Price }_{i t}, \text { Income }_{i t}, X_{i t}, \alpha_{i}\right) \\
& \quad=\Phi\left(\beta_{0}+\beta_{1} \text { Price }_{i t}+\beta_{2} \text { Price }_{i t}+\beta_{3} \text { Income }_{i t}+\beta_{4} X_{i t}+\alpha_{i}\right)
\end{aligned}
$$

In the above equation, current smoker is the current cigarette smoker (either FM or RYO), the current FM cigarette smoker and the current RYO cigarette smoker in models 1,2 , and 3, respectively. $\Phi($.$) is the cumulative distribution function of the$ standard normal distribution, while $\alpha_{i}$ is the individual specific random effect. For individual $i$ at time $t$, Price 1 is the price of FM cigarettes and Price 2 is the price of RYO cigarettes. Income is represented as the four-category variable, while $X$ represents other socioeconomic variables, including age, gender, urban residence, residence in Lusaka, education, occupation and health status variables.

The use of random effects models is preferred over fixed effects models for two reasons:

A. because the fixed effects models would lose observations for those respondents who appear only once in the panel $(41 \%$ of observations)

B. because the fixed effects model would not allow for the identification of the effect of any variable with no within-individual variation (eg, gender) or little within-individual variation (eg, income) over time.

It might be unrealistic to assume that the error terms between model 2 and model 3 are uncorrelated, since the decisions to smoke RYO and FM cigarettes are most likely linked. This issue is addressed by estimating the bivariate probability of RYO and FM cigarette smoking participation (simultaneous equations of model 2 and model 3) using bivariate seemingly unrelated random effects probit (model 5), where the error terms from the two models are allowed to be correlated:

Model 4:

$$
\begin{aligned}
& \operatorname{Pr} \text { (current factorymade cigarette smoker }{ }_{i t} \\
& \left.\quad=1 \mid \text { Price }_{i t}, \text { Price }_{i t}, \text { Income }_{i t}, X_{i t}, \pi_{i}\right) \\
& \quad=\Phi\left(\gamma_{0}+\gamma_{1} \text { Price }_{i t}+\gamma_{2} \text { Price }_{i t}+\gamma_{3} \text { Income }_{i t}+\gamma_{4} X_{i t}+\pi_{i}\right)
\end{aligned}
$$

$$
\begin{aligned}
& \operatorname{Pr} \text { (current RYO cigarette smoker } \\
& \left.\quad=1 \mid \text { Price }_{i t}, \text { Price }_{i t}, \text { Income }_{i t}, X_{i t}, \vartheta_{i}\right) \\
& \quad=\Phi\left(\delta_{0}+\delta_{1} \text { Price }_{i t}+\delta_{2} \text { Price }_{i t}+\delta_{3} \text { Income }_{i t}+\delta_{4} X_{i t}+\vartheta_{i}\right)
\end{aligned}
$$


Table 2 Inflation-adjusted cigarette prices in Zambia in 2014 (kwacha per stick)

\begin{tabular}{|c|c|c|c|c|c|c|c|c|}
\hline & \multicolumn{2}{|c|}{ Wave 1} & \multicolumn{2}{|c|}{ Wave 2} & \multicolumn{2}{|c|}{ Waves 1 and 2 combined } & \multirow{2}{*}{$\begin{array}{l}\text { Between-wave } \\
\text { price change } \\
\%\end{array}$} & \multirow[b]{2}{*}{$P$ values* } \\
\hline & mean & $\mathbf{n}$ & mean & $\mathbf{n}$ & mean & $\mathbf{n}$ & & \\
\hline \multicolumn{9}{|l|}{ Factory-made cigarettes } \\
\hline Last-purchase price & 0.54 & 640 & 0.62 & 571 & 0.58 & 1211 & +15 & 0.001 \\
\hline Spending-based price & 0.52 & 434 & 0.46 & 440 & 0.49 & 874 & -12 & 0.054 \\
\hline Combined price & 0.54 & 650 & 0.62 & 585 & 0.58 & 1235 & +15 & 0.003 \\
\hline \multicolumn{9}{|l|}{ Roll-your-own cigarettes } \\
\hline Last-purchase price & 0.13 & 24 & 0.29 & 110 & 0.26 & 134 & +123 & 0.542 \\
\hline Spending-based price & 0.07 & 280 & 0.10 & 266 & 0.08 & 546 & +43 & 0.001 \\
\hline Combined price & 0.07 & 298 & 0.16 & 308 & 0.12 & 606 & +129 & 0.045 \\
\hline
\end{tabular}

* $\mathrm{P}$ value for the between-wave mean-comparison test.

\section{RESULTS}

Table 2 summarises last-purchase and spending-based prices of FM and RYO cigarettes, as reported in the ITC Zambia Survey. In both waves, RYO prices were significantly lower than FM prices, but the difference declined over time. The average reported FM cigarette price was almost eight times higher than the RYO cigarette price in the first wave $(t=42.36, P<0.001)$, but then about four times higher in Wave $2(t=9.63 p<0.001)$. This price convergence occurred due to a large increase in RYO prices between waves (an increase by 129\% in the combined RYO prices, $\mathrm{t}=-2.01, \mathrm{P}=0.045)$, compared with only a moderate increase in inflation-adjusted FM prices (a $15 \%$ increase in the combined FM prices, $\mathrm{t}=-2.94, \mathrm{P}=0.003)$. Finally, across waves and products, the spending-based price was lower than the price based on the last purchase, possibly due to under-reporting in the spending-based price.

For smokers of FM, there was a large variation in the reported price, depending on cigarette brand. In 2014, the average reported price varied from 0.35 kwacha (US\$0.03) per stick for Pacific brand to 0.70 kwacha (US\$0.07) per stick for Pall Mall brand. Additionally, respondents reported paying more per stick when buying single cigarette sticks ( 0.65 kwacha or US\$0.06 per cigarette stick), compared with cigarette packs (0.48 kwacha or US\$0.05 per stick) and cartons (0.35 kwacha or US\$0.03 per stick) in 2014. Finally, for those who reported buying cigarette by packs, both the spending-based price (10.2 kwacha per pack) and the price based on the last purchase (9.68 kwacha per pack) in 2014 were similar to cigarette prices reported by the Economist Intelligence Unit for Lusaka (9.00 kwacha for local-brand cigarettes and 11.00 kwacha for Marlboro cigarettes). ${ }^{21}$

Table 3 summarises the results from the five models of cigarette smoking participation in Zambia. The own-price effects for FM and RYO cigarettes on the likelihood of smoking are negative in all models, except for the model of the likelihood of dual use. Those effects are significant for both FM and RYO cigarettes in the model of any cigarette use (model 1) and in models of RYO use (models 3 and 5). Additionally, the own-price effects for FM is positive and significant in the model for dual use. There is also a positive relationship between RYO price and the likelihood of FM cigarette smoking (models 2 and 5) and between FM prices and the likelihood of RYO smoking (models 3 and 5). The cross-price coefficient is, however, significant only for FM cigarette price in RYO smoking, which suggests that RYO cigarettes are substitutes for FM cigarettes.

Table 4 presents the own-price and cross-price probability elasticities of prevalence for RYO and FM based on these results. For FM prices, the estimated price elasticity of smoking prevalence (either FM or RYO cigarettes) is -0.20 . This means that a $10 \%$ increase in FM prices leads to a $2 \%$ relative reduction in smoking prevalence. For RYO prices, the estimated price elasticity of smoking prevalence is -0.02 or -0.03 , depending on the model. The cross-price elasticities between FM prices and RYO use were 0.27 and 0.18 in models 3 and 5, respectively. This means that a $10 \%$ increase in $\mathrm{FM}$ prices leads to a $2.7 \%$ increase in RYO in the standard random effects probit model, but a lesser increase of $1.8 \%$ in the system of equations model.

The results from the models that used fitted values of cigarette prices are presented in online supplementary appendix table S3, while online supplementary appendix table S4 presents elasticities calculated using those models. All cross-price effects are positive and significant in those models. The substitution effect from FM to RYO cigarette use in the event of increase in FM cigarette prices is stronger than the substitution from RYO to FM. Additionally, in those models, the own-price effects are also significant for the FM use.

The reason why the results from the separate probit models (models 2 and 3) vary from those of the seemingly unrelated random effects probit model (model 5) is due to the bias caused by the correlation of disturbance terms between the two equations for FM and RYO in models 2 and 3, which is represented in the system of equations model 5. While the observation-specific disturbances (error terms) are uncorrelated in model 5 $(\mathrm{r}=-0.05 ; 95 \% \mathrm{CI}-0.23$ to 0.14$)$, there is a significant correlation between individual-specific disturbance terms $\left(\pi_{i}\right.$ and $\left.\vartheta_{i}\right)$ $(\mathrm{r}=0.29 ; 95 \%$ CI 0.18 to 0.40$)$, suggesting that, as expected, a person's decision to smoke FM is related to their decision to smoke RYO; this implies that the system of equations approach of model 5 was appropriate, and thus the estimates arising from that approach are superior to those arising from the standard approach.

Women and those who reported good or excellent health were significantly less likely to smoke in each model. Higher income was associated with lower probability of smoking any cigarette type (either FM or RYO), lower probability of RYO smoking and lower probability of dual use but was unrelated to the probability of FM smoking. Older respondents were less likely to smoke FM and more likely to smoke RYO. On the contrary, urban residence and formal education were significantly associated with a higher probability of FM smoking and lower probability of RYO smoking. White-collar workers were also significantly less likely to smoke RYO. Finally, residents of the capital city, Lusaka, were more likely to smoke all types of cigarettes, but more so FM, than the rest of the respondents. 
Table 3 Results of probit analyses predicting the probability of cigarette smoking in Zambia

\begin{tabular}{|c|c|c|c|c|c|c|}
\hline \multirow[b]{2}{*}{ Variables } & \multicolumn{4}{|c|}{ Random effects probit models } & \multicolumn{2}{|c|}{$\begin{array}{l}\text { Bivariate seemingly unrelated random } \\
\text { effects probit }\end{array}$} \\
\hline & $\begin{array}{l}\text { All cigarette use } \\
\text { (model 1) }\end{array}$ & $\begin{array}{l}\text { Factory-made } \\
\text { cigarettes use } \\
\text { (model 2) }\end{array}$ & $\begin{array}{l}\text { RYO cigarettes use } \\
\text { (model } 3 \text { ) }\end{array}$ & Dual use (Model 4) & $\begin{array}{l}\text { Factory-made } \\
\text { cigarettes use } \\
\text { (model 5) }\end{array}$ & $\begin{array}{l}\text { RYO cigarettes use } \\
\text { (model 5) }\end{array}$ \\
\hline Price of factory-made cigarettes & $-1.00^{* *}$ & -0.17 & $1.01 * *$ & $1.06^{* * *}$ & -0.30 & $0.91 *$ \\
\hline Price of RYO cigarettes & $-0.73^{* *}$ & 0.05 & $-0.41^{* *}$ & 0.13 & 0.07 & $-0.42^{*}$ \\
\hline \multicolumn{7}{|l|}{$\begin{array}{l}\text { Income status } \\
\text { Below } \$ 1.25 \text { (reference) }\end{array}$} \\
\hline$\$ 1.25$ to $\$ 1.99$ & 0.22 & 0.21 & 0.14 & 0.17 & 0.21 & 0.12 \\
\hline$\$ 2.00$ and above & $-0.25^{*}$ & -0.02 & $-0.65^{* * *}$ & $-0.41^{* * *}$ & 0.01 & $-0.67^{* * *}$ \\
\hline Not reported & $-0.35^{\star *}$ & -0.02 & $-0.32 * *$ & -0.17 & -0.01 & $-0.34^{*}$ \\
\hline Age & 0.001 & $-0.03^{* * *}$ & $0.02 * * *$ & $-0.004^{*}$ & $-0.03^{* * *}$ & $0.02 * * *$ \\
\hline \multicolumn{7}{|l|}{$\begin{array}{l}\text { Gender } \\
\text { Male (reference) }\end{array}$} \\
\hline Female & $-4.25^{* * *}$ & $-2.94^{* * *}$ & $-3.63^{* * *}$ & $-1.78^{* * *}$ & $-2.96^{* * *}$ & $-3.68^{* * *}$ \\
\hline \multicolumn{7}{|l|}{$\begin{array}{l}\text { Urban area of residence } \\
\text { No (reference) }\end{array}$} \\
\hline Yes & -0.01 & $0.95^{* * *}$ & $-2.07^{* * *}$ & $-0.78^{* * *}$ & $0.95^{* * *}$ & $-2.06^{* * *}$ \\
\hline \multicolumn{7}{|l|}{$\begin{array}{l}\text { Residence in Lusaka } \\
\text { No (reference) }\end{array}$} \\
\hline Yes & $0.89 * * *$ & $0.62^{* * *}$ & $-0.45^{* *}$ & -0.02 & $0.64^{* * *}$ & $-0.44^{* *}$ \\
\hline \multicolumn{7}{|l|}{$\begin{array}{l}\text { Education } \\
\text { Low education (reference) }\end{array}$} \\
\hline Primary and higher & -0.14 & $0.91 * * *$ & $-0.49 * * *$ & $0.37^{* * *}$ & $0.95^{* * *}$ & $-0.50 * * *$ \\
\hline \multicolumn{7}{|l|}{$\begin{array}{l}\text { Occupation } \\
\text { Other than white collar (reference) }\end{array}$} \\
\hline White collar & 0.03 & 0.21 & $-2.10^{* * *}$ & $-0.86^{*}$ & 0.22 & $-2.08^{* * *}$ \\
\hline \multicolumn{7}{|l|}{$\begin{array}{l}\text { Self-reported health status } \\
\text { Poor and average (reference) }\end{array}$} \\
\hline Good and excellent & $-0.70 * * *$ & $-0.56^{* * *}$ & $-0.85^{* * *}$ & $-0.44^{* * *}$ & $-0.52^{* * *}$ & $-0.84^{* * *}$ \\
\hline Constant & $6.67^{* * *}$ & $2.30 * * *$ & $5.59 * * *$ & $1.16^{* * *}$ & $2.32 * * *$ & $5.67 * * *$ \\
\hline
\end{tabular}

Number of observations: 3740 .

${ }^{*} \mathrm{P}<0.1 ;{ }^{* *} \mathrm{P}<0.05 ;{ }^{* * *} \mathrm{P}<0.01$

RYO, roll your own.

\section{DISCUSSION}

Higher prices for both FM and RYO cigarettes are significantly related to a reduced likelihood of smoking in Zambia. The estimated value of smoking prevalence elasticity for FM cigarettes $(-0.20)$ is within the range usually observed in LMICs (between -0.10 and -0.40$).{ }^{10} \mathrm{~A}$ large body of evidence demonstrates that effects of this magnitude make cigarette price increases the most effective policy instrument to discourage smoking. ${ }^{10}$ Thus, in Zambia, increasing excise tax on cigarettes in order to drive price increases will be an effective tool to improve public health and reduce tobacco-related costs.

As a party to the WHO FCTC (since 2008), Zambia is obliged to impose high cigarette taxes. ${ }^{16}$ Zambia applies an ad valorem excise with a specific floor. The ad valorem tax rate has remained unchanged for the last decade. Although the specific floor was raised from 90 to $200 \mathrm{kwach}$ in 2016, which is expected to increase the price at the lower end, this increase was barely reflected in cigarette price increase on average. As mentioned above, Zambia has one of the lowest excise tax shares of cigarette price in the world. ${ }^{8}$

One of the reasons for low tobacco taxes in Zambia is likely that some sectors of the government are focused on encouraging tobacco production, processing and manufacturing, a clear discrepancy between short-term economic goals and tobacco control commitments. ${ }^{22}$ Therefore, in order to significantly increase cigarette taxes, the Zambian Ministry of Health and civil society should actively engage in the formulation of the new policies and demonstrate to finance officials that controlling tobacco use is in the long-term best interest of the economic health of the country. Fortunately, there is evidence of significant public support for higher cigarette taxes in the country, even among smokers themselves. Most respondents to the 2014 ITC Zambia Survey (78\%), including nearly three-quarters of smokers (74\%), thought that their

Table 4 The estimates of own-price and cross-price elasticities of prevalence for factory-made and RYO cigarettes in Zambia

\begin{tabular}{lllllll}
\hline & \multicolumn{2}{l}{ Random effects probit } & & \multicolumn{3}{c}{ Bivariate seemingly unrelated random effects probit } \\
\cline { 2 - 3 } & All cigarette use & Factory-made cigarette use & RYO cigarette use & & Factory-made cigarette use & RYO cigarette use \\
\hline Factory-made cigarette price & $-0.20^{* *}$ & -0.05 & $0.27^{* *}$ & -0.14 & $0.18^{*}$ \\
RYO cigarette price & $-0.03^{* *}$ & 0.004 & $-0.03^{* *}$ & 0.01 & $-0.02^{*}$ \\
\hline${ }^{*} \mathrm{P}<0.1 ;{ }^{* *} \mathrm{P}<0.05 ;{ }^{* * *} \mathrm{P}<0.01$. & & & &
\end{tabular}


government should increase taxes on cigarettes. ${ }^{2}$ Future tobacco tax increases in Zambia must take into account both the country's high inflation rates and rapid income growth.

Another factor that must be considered in the crafting of new tax policies is the extensive use of RYO tobacco. Although the price for RYO increased substantially between the waves of the study, possibly influenced by a spike in prices of raw tobacco exported from Zambia, ${ }^{23} \mathrm{RYO}$ remains much cheaper to use than FM cigarettes. Positive cross-price elasticities between FM and RYO cigarettes found in this study suggest that these two products are substitutes; that is, when the price of one of the products goes up, some smokers switch to using the other product. In our models, this cross-price effect is particularly significant for the impact of FM prices on RYO use. Cross-price effect for the impact of RYO prices on FM use was also positive and significant in models that used fitted values of cigarette prices (online supplementary appendix table S3), indicating that FM and RYO cigarettes are substitutes in Zambia.

This switching behaviour weakens the impact of tax increases on improving public health. As a remedy, both the WHO and the implementation guidelines for Article 6 of the WHO FCTC recommend taxing all tobacco products comparably to reduce the between-product price differences, thus disincentivising substitution. ${ }^{8} 24$ Zambia, however, already applies the same ad valorem excise tax rates for RYO tobacco and FM, although the extent of tax compliance for RYO is unknown. Thus, the between-product price differences must be reduced by other means than equalising the tax rates.

There are three viable strategies to reduce price differential between RYO and FM. First, Zambia should consider changing its tax structure and instead apply an excise tax that is specific based or mixed (a combination of ad valorem and specific) with a strong specific component. In the current tax system, which is based on the ad valorem tax, RYO tobacco is tax advantaged. Specifically, because the net price of RYO tobacco is lower than the price of an equivalent amount of FM cigarettes, the ad valorem tax on RYO tobacco will be lower than the tax on FM cigarettes. Relying on specific tax for both FM and RYO would mitigate this advantage and close the price gap markedly. A specific-based system would, however, require frequent changes in the tax rates to adjust for inflation and income growth. Therefore, the best practice is to set the tax rates to increase automatically. The one advantage of the current, ad valorem-based system is that the value of the tax follows changes in cigarette prices.

Second, the country could consider stronger measures to increase enforcement and enhance tax compliance on RYO. This, however, could be difficult because much of the RYO tobacco comes straight from the fields with minimal processing, using mostly traditional methods, with the local market forces determining the price.

Third, the government should strongly consider backing away from promoting tobacco growing and processing. Although the government support for tobacco growing is intended to promote exports, ${ }^{22}$ it directly violates Zambia's commitment to the WHO FCTC, and it seems that this policy has had unintended consequences: local farmers are now also supplying tobacco for RYO, a lower priced combustible tobacco product that people substitute for when the price of FM goes up. Thus, by increasing the supply of RYO, tobacco farming contributes to the very problem that needs to be addressed.

Focusing on the problems arising from RYO will be particularly important because of the socioeconomic status of RYO users. This study finds that, unlike for FM, RYO use is associated with lower income and education and with rural residence.
Therefore, government policies aiming to decrease health inequalities in the society and reduce the negative economic consequences of tobacco use experienced by the poor must incorporate approaches to reducing RYO use, including especially the tax/price approaches that are the focus of this article and cessation efforts directed on those communities.

Besides substituting with RYO, FM cigarette smokers in Zambia can avoid paying higher cigarette prices by trading down to cheaper brands of FM cigarettes. A previous study based on the 2014 wave of the ITC Zambia Survey found that higher price was significantly associated with brand switching. $^{25}$ The significant dispersion in prices of FM in Zambia allows smokers opportunity to trade down to cheaper brands. This again suggests that Zambia should consider changing the excise tax structure to a structure that is based on specific tax, because it would reduce the between-brand variation in cigarette prices. ${ }^{26}$

This study contributes to research aiming to advance the methods to estimate demand for multiple tobacco products. A method often used in the field to analyse cross-price elasticities for different tobacco products is to estimate models for each product separately. ${ }^{10}$ This method assumes that the decision processes pertaining to the choices of two tobacco products are unrelated. The seemingly unrelated regression method, which is used less often in the literature (eg, for substitution between FM and RYO cigarettes ${ }^{2728}$ ) permits correlation between error terms. We found that, in our case, the assumptions of the standard methods were violated. Error terms between equations are correlated in our study, suggesting that decisions to smoke FM and RYO are linked. In addition, the longitudinal design of the ITC Zambia Survey allowed us to make stronger conclusions about the causal relationships between prices and the use of the two tobacco products. This increased methodological sophistication demonstrates the advantage of cohort studies like ITC to facilitate less-biased estimates of critically important parameters such as price elasticities and cross-price elasticities, relative to repeat cross-sectional designs. It is critically important for policymakers to have the least biased estimates of key parameters.

\section{Limitations}

A limitation of this study is that the price measures used in the models are based on self-reported prices. While we addressed the endogeneity problem resulting from the simultaneity of price and consumption, we could not eliminate other issues with the data. First, both the last-purchase price and the spending-based price are subject to recall bias, while the spending-based price can also be subject to under-reporting of the number of cigarettes smoked. It should be noted, however, that the longitudinal design allows for control of the individual-level unobservable characteristics, which should capture some of the respondents' biases.

Second, those two measures represent slightly different prices: one is the last-purchase price, while the other represents the average purchase price for the last 30 days. With many observations, the last-purchase prices should, however, average out to the average purchase price. Unfortunately, too, for some observations, the last-purchase price of RYO could not be calculated, because the respondents' verbal description of the amount of RYO purchased did not allow us to convert to grams. For those observations, we had to rely on the spending-based price. Finally, the spending based-price could not be calculated for dual users of FM and RYO, as the number of cigarettes smoked per day per each cigarette type was not reported in the survey. Because each of the price measures had significant limitations, none could 
be used in the models independently. Combining those two measures is not ideal, because they are different. Nevertheless, the availability of two independent price measures allowed us to triangulate the results. In consequence, we were able to estimate price effects of both anticipated sign and magnitude. The results are robust, with the models on fitted values of cigarette prices yielding results that are of the same direction, similar significance, though of a higher magnitude, compared with the models on the averaged prices.

\section{CONCLUSIONS}

There is scant evidence pertaining to price and cross-price elasticities for tobacco products. This is the first extensive study of price and cross-price elasticities for tobacco products in African and therefore significantly contributes to the limited global evidence from LMICs on the impact of tobacco product prices on between-product substitution.

We used a longitudinal design of the ITC Zambia Survey, estimating a system of equations with panel data, a method that was later found superior over the standard estimation techniques. The longitudinal study design enabled the determination of a temporal and causal relationship between price and the use of FM and RYO cigarettes.

Our findings suggest that FM and RYO cigarettes are substitutes in Zambia, thereby emphasising the need for effective policies to reduce between-product price differences, a factor that undermines the effectiveness of tobacco tax policies. Furthermore, consistent with abundant evidence from high-income countries and a growing body of literature from LMICs, this study affirms that increasing cigarette tax and price in Zambia can markedly reduce cigarette use. Hence, increasing tobacco taxes resulting in higher cigarette prices improves public health and alleviates the detrimental effects of tobacco use and results in higher government revenue in developing economies that are in dire need of the additional income.

\section{What this paper adds}

In 2016, the US National Cancer Institute and the WHO concluded that research studies on cross-price effects on tobacco products use in any country are scarce and practically non-existent for low-income and middle-income countries. The few existing studies generally show that when the ratio of tobacco product prices changes, consumers often choose to switch between products. This has enormous implications for tobacco tax policy in that it suggests tax parity across products when substitution of similarly harmful products such as factory-made (FM) and roll-your-own (RYO) cigarettes is likely.

- The longitudinal design of the International Tobacco Control Zambia Survey permits stronger inferences about causal relationships among price and the use of FM and RYO cigarettes, while the use of a system of equations allows for more precise analyses of the impact of price on the use of FM and RYO cigarettes and of the degree of their substitutability.

- This study is the first study of price and cross-price elasticities for tobacco products in a sub-Saharan African country. The findings from this study can be used by policymakers seeking to reduce tobacco product use through tax-induced price increases and advance public health by designing tax policies intended to decrease the between-product price differentials.
Correction notice This article has been corrected since it was published Online First. Additional details about support were added to the Funding section.

Acknowledgements The authors would like to acknowledge and thank all those that contributed to the ITC Zambia Project, all study investigators, the project managers at University of Waterloo, the collaborators at the University of Zambia, and their field teams for their dedicated efforts in collecting data. We are also thankful to our collaborators at the Republic of Zambia Ministry of Health. Finally, we are grateful to John Daniel for editing assistance.

Contributors MS, NN, JD and GTF contributed to the study design. MS conducted the multivariate analysis and wrote the first draft of the manuscript. All authors contributed to interpretation of results and to refinement, writing and editing of the final manuscript.

Funding The ITC Zambia Project (Waves 1 and 2) was supported by a grant from the Canadian Institutes of Health Research (MOP-115016). Geoffrey T. Fong was supported by a Senior Investigator Grant from the Ontario Institute for Cancer Research. Additional support in preparing this paper was provided to University of Waterloo by the Canadian Institutes of Health Research (FDN-148477).

Competing interests None declared.

Patient consent Not required.

Ethics approval Office of Research Ethics, University of Waterloo, Canada and the University of Zambia Biomedical Research Ethics Committee.

Provenance and peer review Not commissioned; externally peer reviewed.

(c) Article author(s) (or their employer(s) unless otherwise stated in the text of the article) 2019. All rights reserved. No commercial use is permitted unless otherwise expressly granted.

\section{REFERENCES}

1 World Health Organization. WHO Global Report on Trends in Prevalence of Tobacco Smoking 2015. Genev a, Switzerland: World Health Organization, 2015.

2 Project ITC. ITC Zambia National Report. Findings from the Wave 1 and 2 Surveys (2012-2014). Wate rloo, Ontario, Canada: University of Waterloo, 2015.

3 Institute for Health Metrics and Evaluation. Global Burden of Disease Study 2015. Seattle, United Stat es: Institute for Health Metrics and Evaluation, 2016.

4 Chelwa G, Van Walbeek C. Assessing the Causal Impact of Tobacco Expenditure on Household Spending Patterns in Zambia. Economic Research Southern Africa. 2014 http://econpapers.repec.org/paper/rzawpaper/453.htm (accessed 4 Mar 2017).

5 International Monetary Fund. World Economic Outlook Database. 2017 http://www. imf.org (accessed 9 Dec 2014).

6 Chelwa G. The tobacco story in Zambia: a demand, supply and tax analysis. 2012 https://sites.google.com/site/grievechelwa/research (accessed 9 Mar 2017).

7 World Health Organization. WHO report on the global tobacco epidemic 2017: Monitoring tobacco use and prevention policies. Geneva, Switzerland: World Health Organization, 2017

8 World Health Organization. WHO Report on the Global Tobacco Epidemic, 2015: Raising taxes on tobacco. Geneva, Switzerland: World Health Organization, 2015

9 Zambia Revenue Authority. Budget 2016: Overview of Tax Changes. Lusaka: Zambia Revenue Authority, 2016.

10 IARC. IARC Handbooks of Cancer Prevention, Tobacco Control, Vol. 14: Effectiveness of Tax and Price Policies for Tobacco Control. Lyon: International Agency for Research on Cancer, 2011.

11 U.S. National Cancer Institute and World Health Organization. The Economics of Tobacco and Tobacco Control. National Cancer Institute Tobacco Control Monograph 21. Bethesda, MD: U.S.Department of Health and Human Services, National Institutes of Health, National Cancer Institute and World Health Organization, 2016. NIH Publication No. 16-CA-8029A.

12 Van Walbeek C. The economics of tobacco control in South Africa. 2005 http:// tobaccoecon.org/wp-content/uploads/2014/09/van-walbeekcp-the-economics-oftobacco-control-in-south-africa1.pdf (accessed 19 Sep 2016).

13 ITC Project. Zambia. 2017 http://www.itcproject.org/countries/zambia (accessed 16 Aug 2017).

14 Bjartveit K, Tverdal A. Health consequences of smoking 1-4 cigarettes per day. Tob Control 2005;14:315-20.

15 Aqua-Calc. Volume to Weight conversion. $2017 \mathrm{http}: / /$ www.aqua-calc.com/calculate/ volume-to-weight (accessed 9 Feb 2017).

16 United States Government Accountability Office. Large Disparities in Rates for Smoking Products Trigger Significant Market Shifts to Avoid Higher Taxes. 2012 http:// www.gao.gov/assets/600/590192.pdf (accessed 9 Feb 2017).

17 Gallus S, Lugo A, Ghislandi S, et al. Roll-your-own cigarettes in Europe: use, weight and implications for fiscal policies. Eur J Cancer Prev 2014;23:186-92.

18 Liber AC, Warner KE. Has Underreporting of Cigarette Consumption Changed Over Time? Estimates Derived from US National Health Surveillance Systems between 1965 and 2015. Am J Epidemiol 2018;187:113-9. 
19 Nargis N, Ruthbah UH, Hussain AK, et al. The price sensitivity of cig arette consumption in Bangladesh: evidence from the International Tobacco Control (ITC) Bangladesh Wave 1 (2009) and Wave 2 (2010) Surveys. Tob Control 2014:23:i39-47.

20 United Nations. Rethinking poverty: Report on the world social situation 2010. New York: United Nations Publications, 2009.

21 Economist Intelligence Unit. World Cost of Living Survey. London, UK: Economist Intelligence Unit, 2017.

22 Lencucha R, Drope J, Labonte R, et al. Investment incentives and the implementation of the Framework Convention on Tobacco Control: evidence from Zambia. Tob Control 2016:25:483-7.

23 United Nations. UN Comtrade Database. 2017 comtrade.un.org/data/ (accessed 16 Aug 2017).
24 WHO FCTC. Guidelines for implementation of Article 6 of the WHO FCTC. Moscow, Russia:WHO FCTC, 2014.

25 Salloum RG, Goma F, Chelwa G, et al. Cigarette price and other factors associated with brand choice and brand loyalty in Zambia: findings from the ITC Zambia Survey. Tob Control 2015;24:iii33-40.

26 Shang C, Chaloupka FJ, Zahra N, et al. The distribution of cigarette prices under different tax structures: findings from the International Tobacco Control Policy Evaluation (ITC) Project. Tob Control 2014;23:i23-9.

27 Cornelsen L, Normand C. Is roll-your-own tobacco substitute for manufactured cigarettes: evidence from Ireland? J Public Health 2014;36:65-71.

28 Tait P, Rutherford P, Saunders C. Do consumers of manufactured cigarettes respond differently to price changes compared with their Roll-Your-Own counterparts? Evidence from New Zealand. Tob Contro/ 2015:24:285-9. 